\title{
BMJ Open Seasonality of adverse birth outcomes in women with and without HIV in a representative birth outcomes surveillance study in Botswana
}

\author{
Ellen C Caniglia (D) , ${ }^{1}$ Jasmyn Abrams, ${ }^{2}$ Modiegi Diseko, ${ }^{3}$ Gloria Mayondi, ${ }^{3}$ \\ Judith Mabuta, ${ }^{3}$ Joseph Makhema, ${ }^{3}$ Mompati Mmalane, ${ }^{3}$ Shahin Lockman, ${ }^{3,4}$ \\ Aaron Bernstein, ${ }^{5}$ Rebecca Zash, ${ }^{6}$ Roger Shapiro ${ }^{3,5}$
}

To cite: Caniglia EC, Abrams J, Diseko $\mathrm{M}$, et al. Seasonality of adverse birth outcomes in women with and without HIV in a representative birth outcomes surveillance study in Botswana. BMJ Open 2021;11:e045882. doi:10.1136/ bmjopen-2020-045882

- Prepublication history and additional supplemental material for this paper are available online. To view these files, please visit the journal online (http://dx.doi.org/10.1136/ bmjopen-2020-045882).

ECC and JA are joint first authors.

Received 16 0ctober 2020 Accepted 05 August 2021

\section{Check for updates}

(C) Author(s) (or their employer(s)) 2021. Re-use permitted under CC BY-NC. No commercial re-use. See rights and permissions. Published by BMJ.

For numbered affiliations see end of article.

Correspondence to Dr Ellen C Caniglia; ellen.caniglia@pennmedicine. upenn.edu

\section{ABSTRACT}

Introduction Sub-Saharan Africa has the largest number of people with HIV, one of the most severe burdens of adverse birth outcomes globally and particular vulnerability to climate change. We examined associations between seasonality and adverse birth outcomes among women with and without HIV in a large geographically representative birth outcomes surveillance study in Botswana from 2015 to 2018.

Methods We evaluated stillbirth, preterm delivery, very preterm delivery, small for gestational age (SGA), very SGA, and combined endpoints of any adverse or severe birth outcome. We estimated the risk of each outcome by month and year of delivery, and adjusted risks ratios (ARRs) of outcomes during the early wet (1 November-15 January), late wet (16 January-31 March) and early dry (1 April-15 July) seasons, compared with the late dry (16 July-31 October) season. Analyses were conducted overall and separately by HIV status.

Results Among 73178 women (24\% with HIV), the risk of all adverse birth outcomes peaked in November-January and reached low points in September. Compared with the late dry season, the ARRs for any adverse birth outcome were $1.03(95 \% \mathrm{Cl} 1.00$ to 1.06$)$ for the early dry season, $1.08(95 \% \mathrm{Cl} 1.04$ to 1.11$)$ for the early wet season and $1.07(95 \% \mathrm{Cl} 1.03$ to 1.10) for the late wet season. Comparing the early wet season to the late dry season, we found that ARRs for stillbirth and very preterm delivery were higher in women with HIV $(1.23,95 \% \mathrm{Cl} 0.96$ to 1.59 , and $1.33,95 \% \mathrm{Cl} 1.10$ to 1.62 , respectively) than in women without HIV $(1.07,95 \% \mathrm{Cl} 0.91$ to 1.26 , and 1.19 , $95 \% \mathrm{Cl} 1.04$ to 1.36 , respectively).

Conclusions We identified a modest association between seasonality and adverse birth outcomes in Botswana, which was greatest among women with HIV. Understanding seasonal patterns of adverse birth outcomes and the role of HIV status may allow for mitigation of their impact in the face of seasonal extremes related to climate change.

\section{INTRODUCTION}

Reducing preterm birth, small for gestational age (SGA) and stillbirths is a priority for the WHO and United Nations' Every Newborn

\section{STRENGTHS AND LIMITATIONS OF THIS STUDY}

$\Rightarrow$ We use data from more than 70000 women $(24 \%$ with HIV) included in one of the largest birth outcomes surveillance studies in sub-Saharan Africa, which captured $\sim 45 \%$ of all births in Botswana and $>99 \%$ of all births at the included delivery hospitals during the study period.

$\Rightarrow$ We evaluate whether the relationship between season of birth and adverse birth outcomes differs among women with and without HIV.

$\Rightarrow$ We summarise complex seasonal patterns across several years into four categories, which may not fully account for specific weather-related factors and which cannot be disentangled from agricultural practices or other activities specific to these four seasons.

$\Rightarrow$ We are not able to evaluate seasonality of pregnancy loss occurring prior to 24 weeks of gestation.

$\Rightarrow$ Measurement error for preterm delivery and small for gestational age is possible, but not likely to be differential.

Action Plan. ${ }^{1}$ Small babies have the highest risk of death in utero, during the neonatal period and throughout early childhood, and preterm delivery is the leading cause of death among children under $5 .^{1}$ The incidence of these adverse birth outcomes is extremely high in many sub-Saharan African countries. Small babies (preterm or SGA) in southern Asia and sub-Saharan Africa account for more than $80 \%$ of all newborn deaths globally. ${ }^{1}$ In Botswana, the risk of stillbirth is 3.3\%; preterm delivery is $19.6 \%$; and SGA is $13.5 \%,{ }^{2}$ and these risks are higher among the nearly one-quarter of women with HIV. ${ }^{2-12}$ Because the risk of adverse birth outcomes is elevated among women with $\mathrm{HIV}^{2}$ identifying potential interventions in this population is of particularly high importance. 
Understanding seasonal birth patterns may help public health officials predict when adverse birth outcomes are likely to occur and may lead to interventions that can mitigate their impact. Numerous studies have assessed the relationship between season and adverse birth outcomes. ${ }^{13-21}$ These studies have typically focused on the seasonality of preterm birth and birth weight, whereas fewer studies have examined the relationship between season and less common adverse birth outcomes like stillbirth. ${ }^{22}$ Several small studies have been conducted in sub-Saharan Africa, where adverse birth outcomes may be more tightly linked to distinct rainy and dry seasons and related agricultural cycles, ${ }^{16} 182021$ and one meta-analysis of studies conducted in East Africa found an increased risk of preterm birth during the rainy season. ${ }^{17}$ To our knowledge, no studies have assessed how the relationship between seasonality and adverse birth outcomes differs among women with HIV, a population at increased risk of adverse birth outcomes.

Here, we investigate the relationship between season of birth and adverse birth outcomes in Botswana. Botswana is a landlocked country in southern Africa with a semiarid climate, a short rainy season and a dry season characterised by periodic drought. The country suffers from desertification and limited fresh water resources. ${ }^{23}$ We use data from more than 70000 women included in one of the largest birth outcomes surveillance studies in subSaharan Africa over a 4-year period. We also evaluate whether the relationship between season of birth and adverse birth outcomes differs among women with and without HIV.

\section{METHODS}

\section{Tsepamo study}

This study used birth outcomes surveillance data from the ongoing Tsepamo Study in Botswana. Data collection methods have been described elsewhere. ${ }^{12}$ To summarise, data are abstracted from the maternity obstetric record (a record of antenatal care) at the time of delivery from all women delivering at selected hospitals throughout the country. Maternity ward nurses complete the obstetric records, and research assistants and nurses resolve errors or inconsistencies in the records. Tsepamo included eight sites ( $\sim 5 \%$ of all births in Botswana) from August 2014 to July 2018 and 18 sites ( $72 \%$ of all births) from July 2018 to March 2019. The surveillance study captures data on $>99 \%$ of all births that take place at the included sites. $^{12}{ }^{24}$ In Botswana, approximately $95 \%$ of women deliver at a hospital. ${ }^{25}$

Information collected from the maternity obstetric record includes maternal demographic characteristics, medical history, diagnoses, hospitalisation and complications during pregnancy, medications prescribed during pregnancy, HIV history, and clinical information. Gestational age is documented by midwives at the time of delivery based on the estimated date of delivery (EDD). EDD is calculated at the first antenatal care visit using the reported last menstrual period (LMP) and confirmed by ultrasound when available. If the LMP date is unknown or suspected to be incorrect, fundal height measurements are used by the midwives to estimate gestational age.

\section{Inclusion criteria}

Women included in this analysis had at least one antenatal care visit within the first 24 weeks of pregnancy, delivered at or after 24 weeks of gestation, had a known HIV status and gave birth to a singleton between January 2015 and December 2018. We restricted our analyses to the eight delivery sites originally included in Tsepamo (two tertiary referral hospitals in Gaborone and Francistown and six district or primary-level hospitals chosen to create a geographically representative national surveillance system in Maun, Serowe, Molepolole, Selebi-Phikwe, Mahalapye and Ghanzi). Antenatal care is available free of charge in Botswana. All pregnant women are screened for HIV at their first antenatal care visit, and $>95 \%$ of women receive antiretroviral therapy for prevention of mother-to-child transmission. ${ }^{26}$ Since 2016, Botswana's HIV treatment guidelines have recommended antiretroviral therapy for all adults, including pregnant women. ${ }^{27}$

\section{Exposure and outcomes}

The exposures of interest in this study were calendar month, calendar year and season of delivery. Botswana has a 7-month dry season that typically lasts from April to October and a 5-month rainy season that spans November to March. ${ }^{28}$ We divided the seasons into early wet (1 November-15 January), late wet (16 January-31 March), early dry (1 April-15 July) and late dry (16 July-31 October) seasons to capture variation in weather with greater granularity. ${ }^{16}$ The reference season was the late dry period because the highest number of births took place during this time.

The outcomes of interest in this study were preterm delivery ( $<37$ weeks of gestation), very preterm delivery ( $<32$ weeks of gestation), SGA, very small for gestational age (VSGA) and stillbirth (fetal death $\geq 24$ weeks with an Apgar score of 0, 0,0). The combined endpoint of any adverse birth outcome included stillbirth, preterm delivery or SGA, and the combined endpoint of any severe adverse birth outcome included stillbirth, very preterm delivery or VSGA. SGA occurs when an infant's birth weight (measured at delivery) falls below the 10th percentile according to the INTERGROWTH-21st norms, and VSGA occurs when an infant's birth weight falls below the third percentile. ${ }^{29} 30$

\section{Statistical analysis}

We conducted two primary analyses. First, we used line graphs to plot the risk (cumulative incidence) of each adverse birth outcome by calendar month of delivery and by calendar month and year of delivery, overall and separately by HIV status. Second, we estimated risk ratios and $95 \%$ CIs of each adverse birth outcome by season of delivery. To do so, we conducted a series of multivariable 
log-binomial regression models (or Poisson models if the log-binomial models did not converge), ${ }^{31}$ adjusting for HIV status and the following maternal covariates that could be prognostic factors for the outcomes: age $(<25$, 25-30 and $\geq 30$ years or unknown), education (secondary education or higher, other or unknown), marital status (yes, no or unknown), occupation (salaried employment, other or unknown), parity (1 or more, 0 or unknown), smoking during pregnancy (yes, no or unknown), alcohol use during pregnancy (yes, no or unknown), history of stillbirth (yes, no or no prior pregnancy), history of preterm delivery (yes, no or no prior pregnancy) and year of delivery (2015, 2016, 2017 or 2018). Separate models were fit for all women, women with HIV only and women without HIV only. All models were run with and without adjustment for covariates. To evaluate effect modification by HIV status, we compared the risk ratios and $95 \%$ CIs obtained from models restricted to women with HIV only with those obtained from models restricted to women without HIV only.

Additional subgroup analyses were performed to evaluate effect modification by urban versus rural delivery sites. The two delivery sites in Gaborone and Francistown were classified as urban and the other six delivery sites were classified as rural. We estimated the risk of each adverse birth outcome by calendar month of delivery separately for urban and rural delivery sites, and estimated adjusted risk ratios of each adverse birth outcome by season of delivery separately for urban and rural delivery sites. In sensitivity analyses, women with missing age, education, marital status, occupation or parity were excluded, and standard errors were adjusted for clustering by delivery site. All analyses were conducted using R Statistical Software.

\section{Patient and public involvement}

Tsepamo data are collected retrospectively via anonymous chart abstraction. However, the Tsepamo study team seeks input from local partners, including the Botswana-Harvard Partnership and the Botswana Ministry of Health, when developing research questions, analysing findings and interpreting main results.

\section{RESULTS}

Of 95518 women included in Tsepamo delivering at the eight delivery sites between 2015 and 2018, 73178 met our eligibility criteria; $17529(24.0 \%)$ were women with HIV and $55649(76.0 \%)$ were women without HIV. Most women were unmarried (86.5\%), had secondary education or higher $(92.7 \%)$, had other children $(58.3 \%)$, and did not use alcohol $(86.5 \%)$ or smoke $(93.5 \%)$ during pregnancy. Over the 4-year study period, 21823 births (1559/month/year) occurred in the early dry season, $20894(1493 /$ month/year $)$ in the late dry season, 14 $488(1449 /$ month/year $)$ in the early wet season and 15 $973(1597 /$ month/year) in the late wet season (table 1$)$. Women were most likely to give birth in March $(9.1 \%)$ and least likely to give birth in October $(7.6 \%)$ and November $(7.6 \%)$ (data not shown). Maternal characteristics were similar by season of delivery, including age, marital status, educational attainment, employment status, parity, alcohol and tobacco use during pregnancy, and HIV status (table 1). Reported LMP was missing for $9.1 \%$ of women and differed by more than 2 weeks from the EDD for $15.0 \%$ of women.

Figure 1 shows the risk of each adverse birth outcome by month of delivery, separately for each calendar year. The risk of each adverse birth outcome decreased each year from 2015 to 2018. The trends in adverse birth outcomes by month were fairly consistent across the calendar year, though there was a higher risk of SGA in October-November 2015 (19.2\%) compared with the risk of SGA in October-November in 2016-2018 $(14.9 \%-17.5 \%)$.

Figure 2 shows the risk of each adverse birth outcome by month of delivery across all years, overall and separately by HIV status. The lowest risk for any adverse birth outcome was in September $(26.3 \%)$ and the highest risk was in January $(31.1 \%)$. The lowest risk for any severe adverse birth outcome was also in September $(9.0 \%)$ and the highest risk was in November (11.4\%). Risks were higher among women with HIV than among women without HIV for all adverse birth outcomes and across all months. In general, trends in the risk of adverse birth outcome over calendar time were similar when comparing women with and without HIV, with one exception: the risk of adverse birth outcomes was higher in women with HIV, but lower in women without HIV, in May-June.

Overall risks and risk ratios for each adverse birth outcome by season of delivery and HIV status are summarised in table 2 . Risks were highest in the early wet season (1 November-15 January) for stillbirth (2.39\%), preterm delivery $(15.62 \%)$, very preterm delivery $(3.98 \%)$, any adverse birth outcome $(30.57 \%)$ and any severe adverse birth outcome (10.98\%), whereas risks were highest in the late wet season (16 January-31 March) for SGA $(16.85 \%)$ and VSGA $(6.54 \%)$. Compared with the late dry season (16 July-31 October), the adjusted risk ratios for any adverse birth outcome were 1.03 (95\% CI 1.00 to 1.06 ) for the early dry season (1 April-15 July), 1.08 (95\% CI 1.04 to 1.11 ) for the early wet season (1 November-15 January) and 1.07 (95\% CI 1.03 to 1.10$)$ for the late wet season (16 January-31 March). Compared with the late dry season (16 July-31 October), the adjusted risk ratios for any severe adverse birth outcome were 1.00 (95\% CI 0.94 to 1.06) for the early dry season (1 April-15 July), 1.16 (95\% CI 1.09 to 1.24 ) for the early wet season (1 November-15 January) and 1.11 (95\% CI 1.05 to 1.18) for the late wet season (16 January-31 March). The greatest difference for an individual outcome occurred for very preterm delivery; the adjusted risk ratio was 1.24 (95\% CI 1.11 to 1.38 ) when comparing the early wet season (1 November-15 January) with the late dry season (16 July-31 October). 
Table 1 Demographic characteristics by season of delivery, Tsepamo 2015-2018

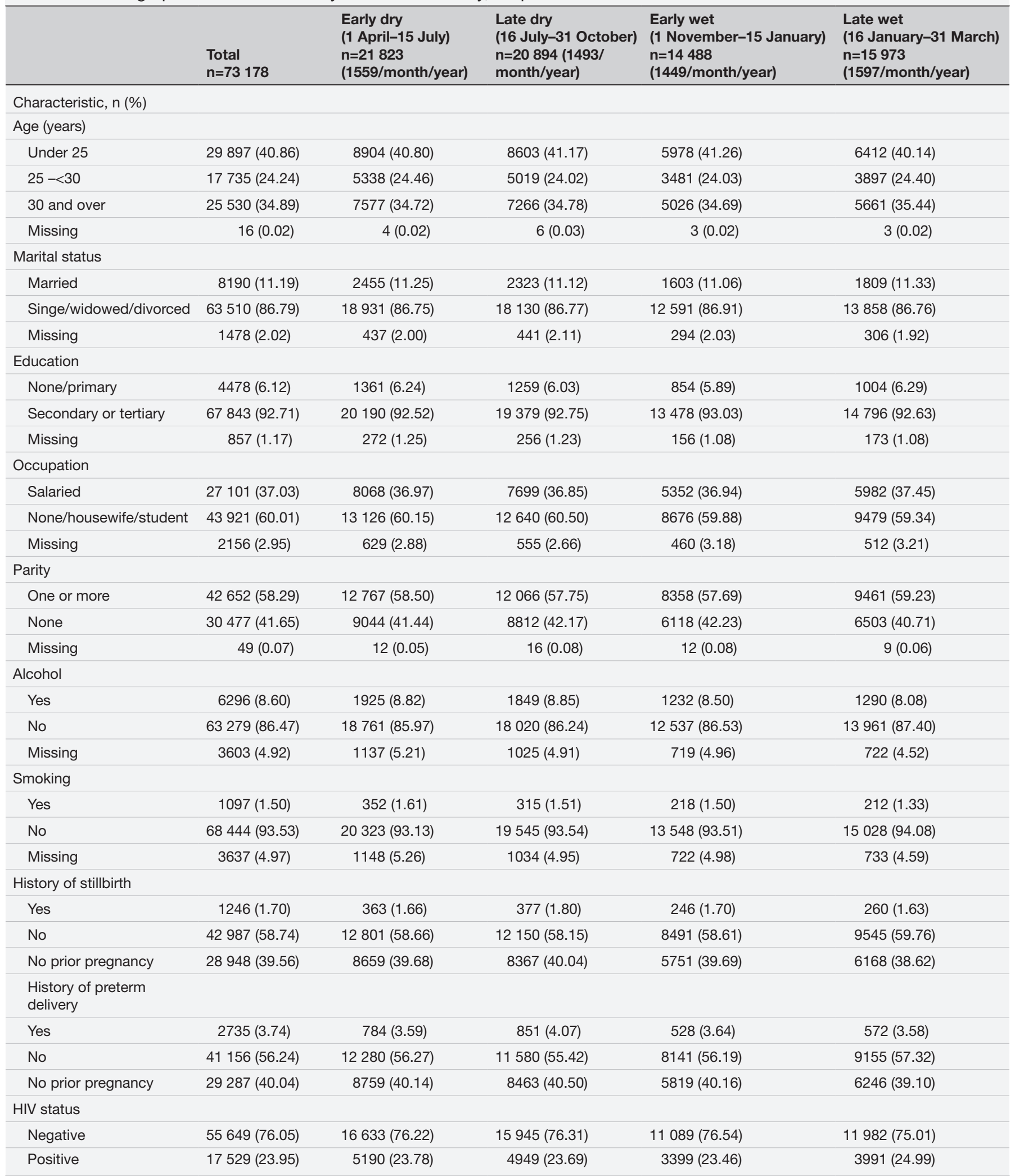

Adjusted risk ratios for stillbirth were higher among women with HIV compared with women without HIV when comparing the early dry season to the late dry season (1.23 (95\% CI 0.97 to 1.54 ) among women with HIV and 1.00 (95\% CI 0.87 to 1.17 ) among women without HIV) and when comparing the early wet season to the late dry season (1.23 (95\% CI 0.96 to 1.59) among women with HIV and 1.07 (95\% CI 0.91 to 1.26 ) among women without HIV) (table 3). Adjusted risk ratios for very preterm delivery were also higher among women 

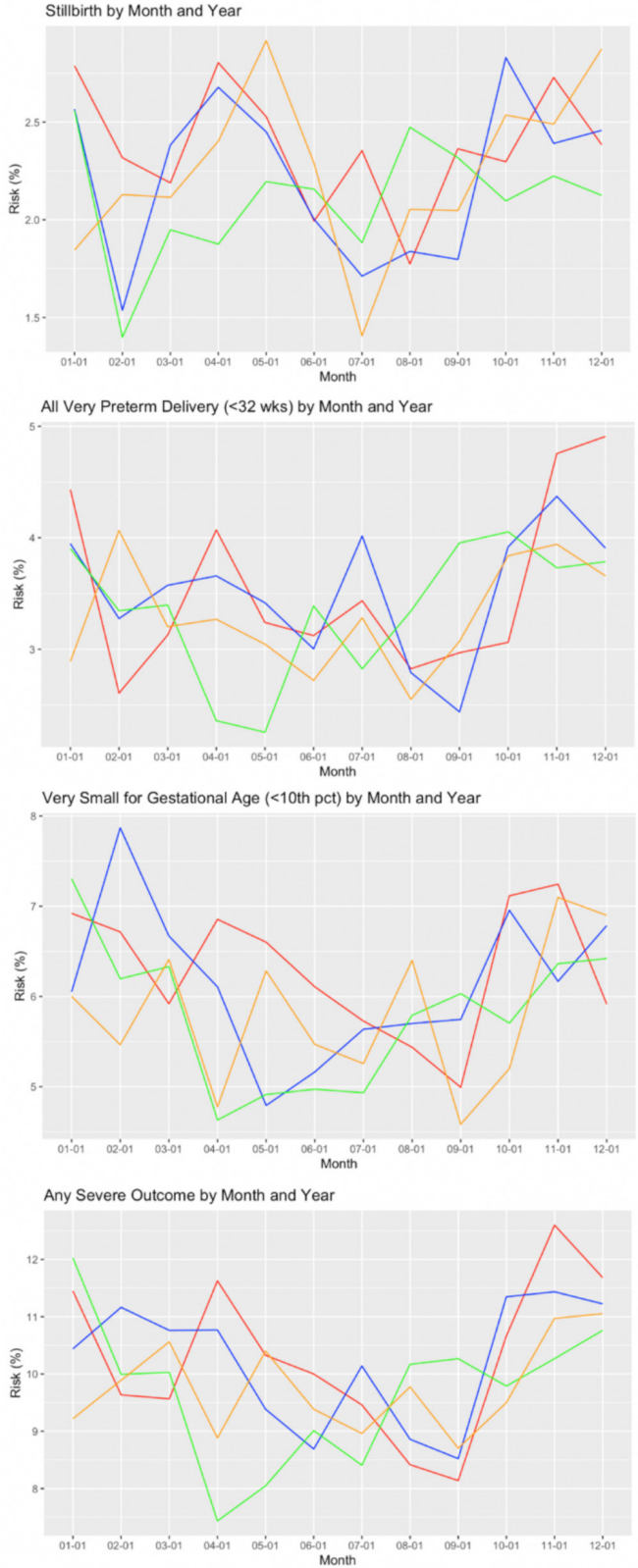
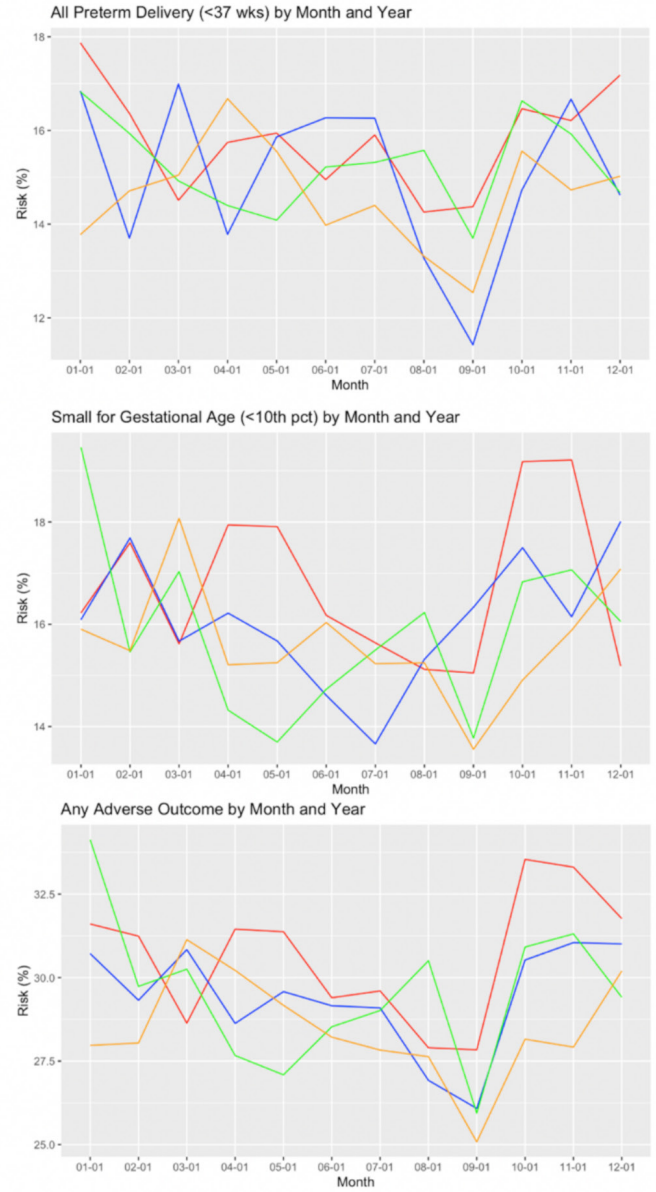

2015

2016

2017

2018 with HIV compared with women without HIV when comparing the early wet season to the late dry season (1.33 (95\% CI 1.10 to 1.62 ) among women with HIV and 1.19 (95\% CI 1.04 to 1.36 ) among women without HIV) (table 3). Adjusted risk ratios were similar for the other adverse birth outcomes when comparing women with and without HIV (table 3).

In general, risks in adverse birth outcomes were higher among women delivering at the two urban delivery sites $(n=35$ 354) than among women delivering at the six rural delivery sites $(n=37824)$, and trends over calendar time were similar in both subgroups (online supplemental appendix figure 1). Adjusted risk ratios for stillbirth, VSGA and any severe adverse birth outcome were higher among women delivering at urban delivery sites compared with women delivering at rural delivery sites when comparing the early and late wet seasons to the late dry season, but similar for the other adverse birth outcomes when comparing women delivering at urban and rural delivery sites (online supplemental appendix table 1). Excluding the 4068 women with missing age, education, marital status, occupation, or parity and adjusting standard errors for clustering by delivery site did not materially change our estimates (online supplemental appendix table 2).

\section{DISCUSSION}

We used a large birth outcomes surveillance study in Botswana to investigate the risk of adverse birth outcomes by season of delivery and to explore effect modification by HIV status. We found variation in the overall number of deliveries and the risk of adverse birth outcomes by 

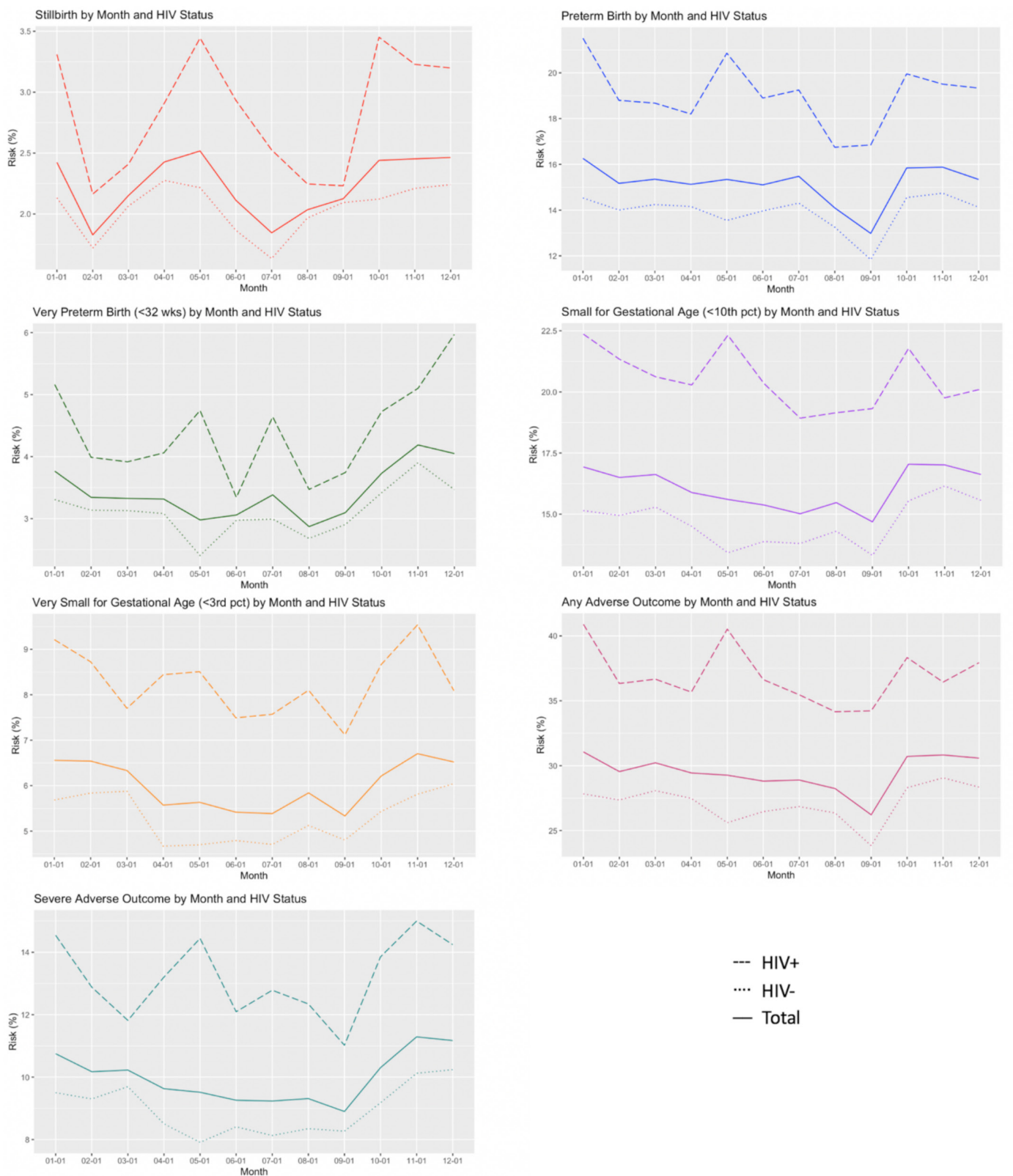

$$
\begin{array}{ll}
\text {--- HIV+ } \\
\text {... HIV- } \\
\text { - Total }
\end{array}
$$

The y-axis changes depending on the outcome of interest.

Figure 2 Risk of each adverse birth outcome by month of delivery and HIV status, Tsepamo 2015-2018.

month and season of delivery. The average monthly number of deliveries was lowest in the early wet season from 1 November to 15 January and highest in the late wet season from 16 January to 31 March, with the peak in March and trough in October-November. The risk of all adverse birth outcomes peaked in November-January during the early wet season and reached low points in September during the late dry season. These elevated risks were more pronounced in women with HIV for stillbirth and very preterm delivery.

Our findings are consistent with several studies conducted in sub-Saharan African countries that found higher birth weights in the dry season (and at the end of the harvest season ${ }^{32}{ }^{33}$ ) and lower birth weights in the wet season, ${ }^{193435}$ and with a meta-analysis of studies conducted in East Africa that found an increased risk of preterm birth during the wet season. ${ }^{17}$ In contrast, a small study in Zimbabwe found the odds of preterm birth in the early dry season were nearly three times the odds of preterm birth in the late wet season ${ }^{16}$; one study in the Gambia found divergent patterns in the seasonality of preterm birth and SGA with the risk of preterm birth peaking in July and October and the risk of SGA highest from August to December ${ }^{20}$; and a small study in South Africa found birth weight peaked in November and reached a trough in July and August. ${ }^{21}$

There are several potential explanations for the elevated risk of all adverse birth outcomes in the early wet season. First, the early wet season (1 November-15 January) overlaps with the sowing season of major food crops in Botswana. ${ }^{28}$ Insufficient nutrition in the third trimester, a risk factor for stillbirth, ${ }^{36}$ low birth weight ${ }^{38}$ 
Table 2 Absolute risks and unadjusted and adjusted risk ratios of adverse birth outcomes by season of delivery, Tsepamo 2015-2018

\begin{tabular}{|c|c|c|c|c|c|c|}
\hline Outcome & $\begin{array}{l}\text { Total } \\
\text { number* }\end{array}$ & $\begin{array}{l}\text { Absolute } \\
\text { risk (\%) }\end{array}$ & $\begin{array}{l}\text { Unadjusted } \\
\text { risk ratio }\end{array}$ & $95 \% \mathrm{Cl}$ & $\begin{array}{l}\text { Adjusted risk } \\
\text { ratio† }\end{array}$ & $95 \% \mathrm{Cl}$ \\
\hline \multicolumn{7}{|l|}{ Stillbirth } \\
\hline Early dry (1 April-15 July) & 497 & 2.28 & 1.06 & 0.94 to 1.21 & 1.07 & 0.94 to 1.21 \\
\hline Early wet (1 November-15 January) & 346 & 2.39 & 1.11 & 0.97 to 1.28 & 1.12 & 0.97 to 1.28 \\
\hline Late wet (16 January-31 March) & 342 & 2.14 & 1.00 & 0.87 to 1.15 & 1.00 & 0.87 to 1.15 \\
\hline Late dry (16 July-31 October) & 3031 & 14.56 & 1.00 & Ref & 1.00 & Ref \\
\hline Early dry (1 April-15 July) & 3311 & 15.17 & 1.05 & 1.00 to 1.09 & 1.05 & 1.00 to 1.10 \\
\hline Early wet (1 November-15 January) & 2263 & 15.62 & 1.08 & 1.02 to 1.13 & 1.08 & 1.03 to 1.14 \\
\hline Late wet (16 January-31 March) & 2486 & 15.56 & 1.07 & 1.02 to 1.13 & 1.08 & 1.02 to 1.13 \\
\hline Early wet (1 November-15 January) & 576 & 3.98 & 1.23 & 1.10 to 1.37 & 1.24 & 1.11 to 1.38 \\
\hline Late wet (16 January-31 March) & 557 & 3.49 & 1.08 & 0.97 to 1.20 & 1.08 & 0.97 to 1.21 \\
\hline \multicolumn{7}{|l|}{ SGA (<10th percentile) } \\
\hline Late dry (16 July-31 October) & 3228 & 15.58 & 1.00 & Ref & 1.00 & Ref \\
\hline Early dry (1 April-15 July) & 3367 & 15.54 & 1.00 & 0.95 to 1.04 & 1.00 & 0.96 to 1.05 \\
\hline Early wet (1 November-15 January) & 2382 & 16.61 & 1.07 & 1.02 to 1.12 & 1.07 & 1.02 to 1.12 \\
\hline Late wet (16 January-31 March) & 2670 & 16.85 & 1.08 & 1.03 to 1.13 & 1.08 & 1.03 to 1.14 \\
\hline \multicolumn{7}{|l|}{ Very SGA (<3rd percentile) } \\
\hline Late Dry (16 July-31 October) & 1192 & 5.75 & 1.00 & Ref & 1.00 & REF \\
\hline Early wet (1 November-15 January) & 4388 & 30.57 & 1.07 & 1.04 to 1.11 & 1.08 & 1.04 to 1.11 \\
\hline Late wet (16 January-31 March) & 4821 & 30.40 & 1.07 & 1.03 to 1.10 & 1.07 & 1.03 to 1.10 \\
\hline \multicolumn{7}{|l|}{ Any severe outcome } \\
\hline Late dry (16 July-31 October) & 1979 & 9.54 & 1.00 & Ref & 1.00 & Ref \\
\hline Early dry (1 April-15 July) & 2053 & 9.47 & 0.99 & 0.94 to 1.05 & 1.00 & 0.94 to 1.06 \\
\hline Early wet (1 November-15 January) & 1576 & 10.98 & 1.15 & 1.08 to 1.23 & 1.16 & 1.09 to 1.24 \\
\hline Late wet (16 January-31 March) & 1667 & 10.51 & 1.10 & 1.04 to 1.17 & 1.11 & 1.05 to 1.18 \\
\hline
\end{tabular}

*5 women had missing data for stillbirth; 0 women had missing data for preterm delivery; and 610 women had missing data for SGA.

†Adjusted for age, marital status, education, occupation, parity, alcohol, smoking, history of preterm delivery, history of stillbirth, delivery year and HIV status.

SGA, small for gestational age.

and preterm delivery, ${ }^{39}$ may be more likely during these months if nutritious foods from the previous harvest are no longer or less readily available. Second, the early wet season overlaps with the holiday season in Botswana. Following the holidays in December, January is often marked by overcrowded and understaffed hospitals and increased financial insecurity. An increased risk of stillbirth in December and January could therefore reflect lack of available transportation to the hospital, understaffed hospitals or difficulty getting to the hospital due to reduced income, though we were not able to distinguish fresh versus macerated stillbirths reliably. Finally, high temperatures in the early wet season ${ }^{40}$ could contribute to an increased risk of preterm delivery (eg, by initiating labour through dehydration or inefficient thermoregulation or by triggering preterm premature rupture of 
Table 3 Absolute risks and adjusted risk ratios of adverse birth outcomes by season of delivery and HIV status, Tsepamo 2015-2018

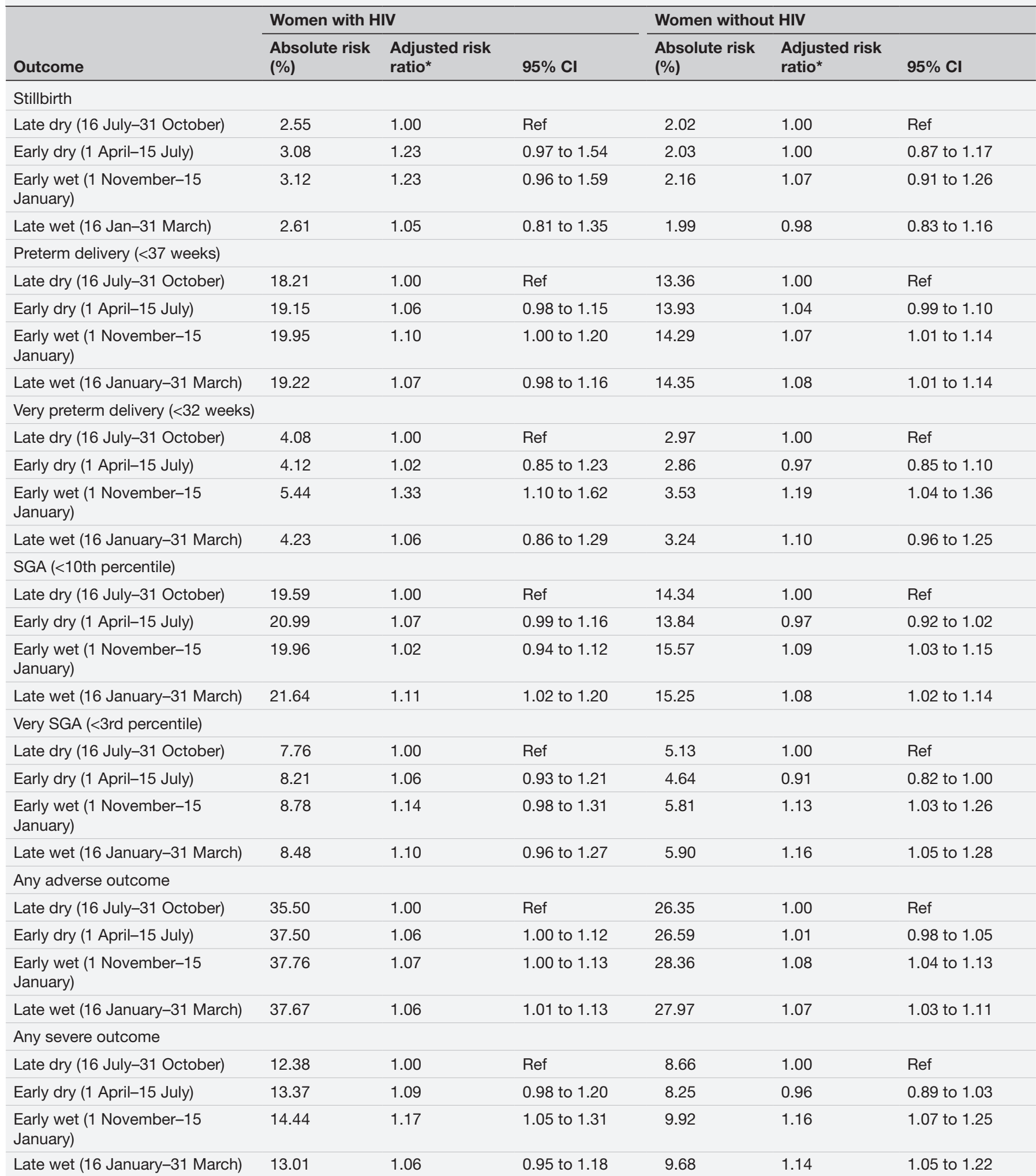

*Adjusted for age, marital status, education, occupation, parity, alcohol, smoking, history of preterm delivery, history of stillbirth and delivery year.

membranes) and stillbirth (eg, through lowering amniotic fluid volume, damage to or abruption of the placenta, or initiating preterm labour). ${ }^{41-43}$
The early dry season (1 April-15 July) overlaps with the harvest season of maize and sorghum, two major food crops in Botswana. ${ }^{28}$ We found lower risks of adverse birth 
outcomes in the early and late dry seasons, which could suggest a link between the harvest season and improved birth outcomes. A possible explanation for this finding is that mothers have more access to nutritious food during this time. In low-income and middle-income countries that rely on local agriculture, birth weight tends to be highest at the beginning of the dry season, when crops are harvested; nutritious food is most plentiful; and physical labour is the least, maximising fetal growth during the last trimester when growth is most critical. ${ }^{34}$ The early and late dry seasons also overlap with seasonal influenza, ${ }^{44} \mathrm{a}$ potential risk factor for adverse birth outcomes,${ }^{45}$ though we found lower risk of adverse birth outcomes during these periods.

Single spikes in adverse birth outcomes that are not consistent across calendar years are more likely to be explained by outlier environmental events than by seasonal variation. In our study, we found an elevated risk of SGA in October of 2015. One potential explanation for this spike was a severe drought in Southern Africa in October-November 2014, during the early stages of the sowing season. ${ }^{46}$ Women conceiving following this unfavourable growing season could have been at elevated risk of SGA, in particular, if the harvest season following the drought was extremely poor. However, our analysis was not designed to identify individual spikes in adverse birth outcomes (or whether spikes occur only in women with or without HIV), and studies are needed to investigate the link between drought and adverse pregnancy outcomes. Further, single spikes could also be attributed to random variation in the risk of adverse outcomes rather than environmental factors.

The higher risk of all adverse birth outcomes among women with HIV compared with women without HIV has been described thoroughly in the literature. ${ }^{2-811}$ However, we also found stronger associations (larger risk ratios) between seasonality and severe adverse birth outcomes (stillbirth and very preterm delivery) among women with HIV, indicating that this population may be more susceptible to environmental and nutritional factors that vary by season, or to seasonal variation in access to and quality of care. Further research is needed to identify low-cost and sustainable interventions that could reduce the risk of adverse birth outcomes in women with HIV. Because the risk of an adverse birth outcome is already high among women with HIV (35\%), even modest decreases in risk can have substantial impacts. However, the $95 \%$ CIs around our estimates for these severe adverse birth outcomes in women with and without HIV were overlapping, and the clinical significance of the larger risk ratios for women with HIV compared with women without HIV may be limited. Differences in risks and risk ratios of adverse birth outcomes stratified by urban versus rural delivery site could be explained by the urban delivery sites being primary referral hospitals that are more likely to serve women with pregnancy complications and women with HIV, or due to other differences in nutritional and environmental factors.
Our study had several additional limitations. We have summarised complex seasonal patterns across several years into four categories, which may not fully account for specific weather-related factors (such as temperature, rainfall or extreme weather events) and which cannot be disentangled from agricultural practices or other activities (eg, holiday periods) specific to these four seasons. We were not able to evaluate seasonality of pregnancy loss occurring prior to 24 weeks of gestation. While the increase in deliveries in the late wet season compared with the early wet season could indicate increased conception in the early dry season (three seasons prior to the late wet season), it could also indicate more early pregnancy loss in the late wet season (three seasons prior to the early wet season). We evaluated birth outcomes by month and season of delivery rather than by month and season of conception, but unique and distinct first trimester risks could provide alternate explanations for our findings that were not explored. ${ }^{13}$ Measurement error for preterm delivery and SGA was possible since gestational age was calculated using the recorded LMP date and maternity nurse assessment. However, it is unlikely that this error would be differential with respect to season of birth. Our study includes data from 4 years, but we were not able to ascertain whether a woman contributed to more than one pregnancy in the data. Finally, the goal of our study was to describe the seasonality of adverse birth outcomes among women with and without HIV. We did not set out to evaluate causal relationships, and our study was not designed to investigate potential climate-related interventions to reduce adverse birth outcomes.

To our knowledge, this is the first study to examine adverse birth outcomes by season of delivery and HIV status. Our finding that the risk of stillbirth was highest in December and January, during the early wet season, may be useful for public health officials to increase surveillance and prevention efforts during this time of high risk. For example, the elevated stillbirth risk of 2.39\% during the early wet season (compared with $2.14 \%$ during the late dry and late wet seasons) represents an excess of 36 stillbirths ( $0.25 \%$ of 14488 births) during the 4-year study period. This number could increase further if seasonal differences in weather conditions and nutritional status of pregnant women are driving our findings, as climate change is likely to promote greater heat exposure and food insecurity in Botswana. ${ }^{47}$ Future studies are needed to determine whether environmental, nutritional or infrastructure-related factors are driving the elevated risk of stillbirth (and other adverse birth outcomes) during these months so that appropriate interventions can be identified, and whether increasing hospital resources in high-risk periods may be warranted. In addition, our finding that the risk of all adverse birth outcomes was higher in the early and late wet season compared with the late dry season suggests that these events may increase or decrease, depending on regional variations in climate change during the coming years. All of these considerations are of particular importance for southern Africa, 
which has the largest number of women with HIV and is also a region especially vulnerable to the effects of global climate change. ${ }^{48} 49$

\section{Author affiliations}

${ }^{1}$ Perelman School of Medicine, University of Pennsylvania, Philadelphia,

Pennsylvania, USA

${ }^{2}$ Department of Population Health, NYU Langone Health, New York, New York, USA

${ }^{3}$ Botswana-Harvard AIDS Institute Partnership, Gaborone, Botswana

${ }^{4}$ Department of Infectious Disease, Brigham and Women's Hospital, Boston,

Massachusetts, USA

${ }^{5}$ Immunology and Infectious Diseases, Center for Climate, Health, and the Global

Environment, Harvard University T.H. Chan School of Public Health, Boston,

Massachusetts, USA

${ }^{6}$ Department of Infectious Diseases, BIDMC, Boston, Massachusetts, USA

Contributors EC and JA designed the study with significant input from RS, SL, AB and RZ. Statistical analyses were conducted by ECC and JA. ECC and JA prepared the first draft of the manuscript. ECC, JA, MD, GM, JMab, JMak, MM, SL, AB, RZ and RS participated in editing the manuscript and approved the final version for submission. The corresponding author had full access to all data and had the final responsibility for the decision to submit for publication.

Funding This study received support from the National Institutes of Health $(\mathrm{IH} /$ NICHD R01 HD080471, NIH/NICHD K23 HD088230-01A1, NIH/NIAID K24Al131924 and NIH/NICHD K01 HD100222-01A1).

Competing interests None declared.

Patient consent for publication Not required.

Ethics approval Institutional approval for Tsepamo was granted by the Health Research and Development Committee in Botswana (HPDME 13/18/1×1) and by the institutional review board of Harvard T.H. Chan School of Public Health in Boston, Massachusetts (IRB14-1352).

Provenance and peer review Not commissioned; externally peer reviewed.

Data availability statement Data are available upon reasonable request. Once the Tsepamo Study has concluded, requests for data can be made, and will be reviewed by the PI and subject to IRB approval in Botswana and the United States.

Supplemental material This content has been supplied by the author(s). It has not been vetted by BMJ Publishing Group Limited (BMJ) and may not have been peer-reviewed. Any opinions or recommendations discussed are solely those of the author(s) and are not endorsed by BMJ. BMJ disclaims all liability and responsibility arising from any reliance placed on the content. Where the content includes any translated material, BMJ does not warrant the accuracy and reliability of the translations (including but not limited to local regulations, clinical guidelines, terminology, drug names and drug dosages), and is not responsible for any error and/or omissions arising from translation and adaptation or otherwise.

Open access This is an open access article distributed in accordance with the Creative Commons Attribution Non Commercial (CC BY-NC 4.0) license, which permits others to distribute, remix, adapt, build upon this work non-commercially, and license their derivative works on different terms, provided the original work is properly cited, appropriate credit is given, any changes made indicated, and the use is non-commercial. See: http://creativecommons.org/licenses/by-nc/4.0/.

ORCID iD

Ellen C Caniglia http://orcid.org/0000-0001-8667-6471

\section{REFERENCES}

1 World Health Organization. Every newborn: an action plan to end preventable deaths 2014

2 Chen JY, Ribaudo HJ, Souda S, et al. Highly active antiretroviral therapy and adverse birth outcomes among HIV-infected women in Botswana. J Infect Dis 2012;206:1695-705.

3 Zash R, Souda S, Chen JY, et al. Reassuring birth outcomes with Tenofovir/Emtricitabine/Efavirenz used for prevention of mother-tochild transmission of HIV in Botswana. J Acquir Immune Defic Syndr 2016;71:428-36.

4 Townsend CL, Cortina-Borja M, Peckham CS, et al. Antiretroviral therapy and premature delivery in diagnosed HIV-infected women in the United Kingdom and ireland. AIDS 2007;21:1019-26.
5 Suy A, Martínez E, Coll O, et al. Increased risk of pre-eclampsia and fetal death in HIV-infected pregnant women receiving highly active antiretroviral therapy. AIDS 2006;20:59-66.

6 Ekouevi DK, Coffie PA, Becquet R, et al. Antiretroviral therapy in pregnant women with advanced HIV disease and pregnancy outcomes in Abidjan, Côte d'Ivoire. AIDS 2008;22:1815-20.

7 Martin F, Taylor GP. Increased rates of preterm delivery are associated with the initiation of highly active antiretrovial therapy during pregnancy: a single-center cohort study. J Infect Dis 2007:196:558-61.

8 Sibiude J, Warszawski J, Tubiana R, et al. Premature delivery in HIV-infected women starting protease inhibitor therapy during pregnancy: role of the ritonavir boost? Clin Infect Dis 2012;54:1348-60.

9 , de Vincenzi I, Kesho Bora Study Group. Triple antiretrovira compared with zidovudine and single-dose nevirapine prophylaxis during pregnancy and breastfeeding for prevention of motherto-child transmission of HIV-1 (Kesho Bora study): a randomised controlled trial. Lancet Infect Dis 2011;11:171-80.

10 Kakkar F, Boucoiran I, Lamarre V, et al. Risk factors for pre-term birth in a Canadian cohort of HIV-positive women: role of ritonavir boosting? J Int AIDS Soc 2015;18:19933.

11 Ahmed S, Kim MH, Abrams EJ. Risks and benefits of lifelong antiretroviral treatment for pregnant and breastfeeding women: a review of the evidence for the option $\mathrm{B}+$ approach. Curr Opin HIV AIDS 2013;8:474-89.

12 Zash R, Jacobson DL, Diseko M, et al. Comparative safety of antiretroviral treatment regimens in pregnancy. JAMA Pediatr 2017;171:e172222

13 Bodnar LM, Simhan HN. The prevalence of preterm birth and season of conception. Paediatr Perinat Epidemiol 2008;22:538-45.

14 Rahman A, Rahman M, Pervin J, et al. Time trends and sociodemographic determinants of preterm births in pregnancy cohorts in Matlab, Bangladesh, 1990-2014. BMJ Glob Health 2019;4:e001462.

15 Lee SJ, Steer PJ, Filippi V. Seasonal patterns and preterm birth: systematic review of the literature and an analysis in a London-based cohort. BJOG 2006;113:1280-8.

16 Friis H, Gomo E, Nyazema N, et al. Maternal body composition, HIV infection and other predictors of gestation length and birth size in Zimbabwe. Br J Nutr 2004:92:833-40.

17 Laelago T, Yohannes T, Tsige G. Determinants of preterm birth among mothers who gave birth in East Africa: systematic review and metaanalysis. Ital J Pediatr 2020;46:10.

18 Osei E, Agbemefle I, Kye-Duodu G, et al. Linear trends and seasonality of births and perinatal outcomes in upper East region, Ghana from 2010 to 2014. BMC Pregnancy Childbirth 2016;16:48.

19 Prentice AM, Cole TJ, Foord FA, et al. Increased birthweight after prenatal dietary supplementation of rural African women. Am J Clin Nutr 1987;46:912-25.

20 Rayco-Solon P, Fulford AJ, Prentice AM. Differential effects of seasonality on preterm birth and intrauterine growth restriction in rural Africans. Am J Clin Nutr 2005;81:134-9.

21 Fahey CA, Chevrier J, Crause M, et al. Seasonality of antenatal care attendance, maternal dietary intake, and fetal growth in the VHEMBE birth cohort, South Africa. PLoS One 2019;14:e0222888.

22 Auger N, Fraser WD, Smargiassi A, et al. Elevated outdoor temperatures and risk of stillbirth. Int J Epidemiol 2017;46:200-8.

23 World Health Organization. Health and climate change: country profile 2015: Botswana, 2015. Available: https://www.who.int/ publications/i/item/health-and-climate-change-country-profile-2015botswana [Accessed April 15, 2021].

24 Zash R, Holmes L, Diseko M, et al. Neural-Tube defects and antiretroviral treatment regimens in Botswana. $N$ Engl $\mathrm{J}$ Med 2019;381:827-840

25 World Health Organization. Botswana: WHO statistical profile, 2015. Available: http://www.who.int/gho/countries/bwa.pdf?ua=1\&ua=1 [Accessed 21 Oct 2019].

26 UNAIDS. Botswana country profile, 2019. Available: https://www. unaids.org/en/regionscountries/countries/botswana [Accessed 15 Apr 2021].

27 Botswana Ministry of Health. Handbook of the Botswana 2016 integrated HIV clinical care guidelines, 2016. Available: http:// apps.who.int/medicinedocs/documents/s22413en/s22413en.pdf [Accessed 13 Sep 2019].

28 Food and Agriculture Organization of the United Nations. GIEWS - Global Information and Early Warning System - Country Brief for Botswana, 2020. Available: http://www.fao.org/giews/countrybrief/ country.jsp?lang=en\&code=BWA [Accessed 08 Jul 2020].

29 Villar J, Cheikh Ismail L, Victora CG, et al. International standards for newborn weight, length, and head circumference by gestational age 
and sex: the newborn cross-sectional study of the INTERGROWTH21st project. Lancet 2014;384:857-68.

30 Villar J, Giuliani F, Fenton TR, et al. INTERGROWTH-21st very preterm size at birth reference charts. Lancet 2016;387:844-5.

31 Spiegelman D, Hertzmark E. Easy SAS calculations for risk or prevalence ratios and differences. Am J Epidemiol 2005;162:199-200.

32 Ceesay SM, Prentice AM, Cole TJ, et al. Effects on birth weight and perinatal mortality of maternal dietary supplements in rural Gambia: 5 year randomised controlled trial. BMJ 1997;315:786-90.

33 Kinabo J. Seasonal variation of birth weight distribution in Morogoro, Tanzania. East Afr Med J 1993;70:752-5.

34 Chodick G, Flash S, Deoitch Y, et al. Seasonality in birth weight: review of global patterns and potential causes. Hum Biol 2009;81:463-77.

35 Fallis G, Hilditch J. A comparison of seasonal variation in birthweights between rural Zaire and Ontario. Can J Public Health 1989;80:205-8.

36 Liu L-C, Wang Y-C, Yu M-H, et al. Major risk factors for stillbirth in different trimesters of pregnancy--a systematic review. Taiwan $J$ Obstet Gynecol 2014;53:141-5.

37 Fretts RC. Etiology and prevention of stillbirth. Am J Obstet Gynecol 2005;193:1923-35.

38 Lumey LH. Reproductive outcomes in women prenatally exposed to undernutrition: a review of findings from the Dutch famine birth cohort. Proc Nutr Soc 1998;57:129-35.

39 Triunfo S, Lanzone A. Impact of maternal under nutrition on obstetric outcomes. J Endocrinol Invest 2015;38:31-8.

40 Alexander KA, Carzolio M, Goodin D, et al. Climate change is likely to worsen the public health threat of diarrheal disease in Botswana. Int J Environ Res Public Health 2013;10:1202-30.
41 Ilango SD, Weaver M, Sheridan P, et al. Extreme heat episodes and risk of preterm birth in California, 2005-2013. Environ Int 2020;137:105541.

42 Bekkar B, Pacheco S, Basu R, et al. Association of air pollution and heat exposure with preterm birth, low birth weight, and stillbirth in the US: a systematic review. JAMA Netw Open 2020;3:e208243.

43 Chersich MF, Pham MD, Areal A, et al. Associations between high temperatures in pregnancy and risk of preterm birth, low birth weight, and stillbirths: systematic review and meta-analysis. BMJ 2020;371:m3811.

44 World Health Organization. Influenza surveillance in the WHO African region, 2017. Available: https://www.afro.who.int/sites/default/files/ 2017-06/afr-influenza-surveillance_epi-weeks-1-to-52.pdf [Accessed 15 Apr 2021]

45 Fell DB, Savitz DA, Kramer MS, et al. Maternal influenza and birth outcomes: systematic review of comparative studies. BJOG 2017;124:48-59.

46 VAM food security analysis. Southern Africa: the 2014-2015 rainfall season. Available: https://documents.wfp.org/stellent/groups/public/ documents/ena/wfp274160.pdf?_ga=2.88071064.1074486920. 1594150535-635459080.1594150535 [Accessed 7 Jul 2020].

47 World Health Organization. Climate and health country profile Botswana, 2015. Available: https://apps.who.int/iris/bitstream/ handle/10665/246151/WHO-FWC-PHE-EPE-15.33-eng.pdf sequence $=1$ [Accessed 3 Sep 2020].

48 Murray CJL, Vos T, Lozano R, et al. Disability-adjusted life years (DALYs) for 291 diseases and injuries in 21 regions, 1990-2010: a systematic analysis for the global burden of disease study 2010. Lancet 2012;380:2197-223.

49 Collier P, Conway G, Venables T. Climate change and Africa. Oxf Rev Econ Policy 2008;24:337-53. 